ORIGINAL ARTICLE

\title{
Real-world Effectiveness of Speech Therapy Time on Cognitive Recovery in Older Patients with Acute Stroke
}

\author{
Kotomi Sakai, SLP ${ }^{\text {a,b }}$, Ryo Momosaki, MD, PhD, MPH ${ }^{\text {c,d }}$
}

\begin{abstract}
Objective: The purpose of this research was to investigate the real-world effectiveness of speech therapy time on cognitive recovery in older patients with acute stroke. Methods: The participants of this retrospective cohort study were hospitalized patients with acute stroke registered in the Japan Rehabilitation Database between December 2005 and September 2014. The patients were divided into two groups according to the amount of time they spent undergoing speech therapy, i.e., a high-intensity speech therapy group and a control group. Multivariate linear regression analysis was performed to assess the association between cognitive Functional Independence Measure efficiency and high-intensity speech therapy. Results: Of the 3341 eligible stroke patients (mean age: 77 years) extracted from the database, 53\% received high-intensity speech therapy. Patients in the high-intensity speech therapy group had significantly higher cognitive Functional Independence Measure efficiency scores than those in the control group (mean, 0.17 vs. 0.10 , respectively; $\mathrm{P}<0.001$ ). Multivariate regression analysis showed that cognitive Functional Independence Measure efficiency was significantly and positively correlated with high-intensity speech therapy (coefficient, $0.03 ; 95 \%$ confidence interval, $0.004-0.056 ; \mathrm{P}=0.026$ ).

Conclusions: These data suggest that a large amount of speech therapy time in older patients with acute stroke is a significant predictor of good cognitive recovery. Increased amounts of speech therapy for such patients may lead to better cognitive recovery after stroke.
\end{abstract}

Key Words: cognitive function; older patients; rehabilitation; speech therapy; stroke

\section{INTRODUCTION}

The world population is rapidly aging, and stroke is the most common disease in aged populations. Stroke causes disability among adults worldwide. ${ }^{1)}$ In older people, stroke is commonly associated with a risk of subsequent cognitive disability, ${ }^{2)}$ which often has a negative effect on dependence in daily activities. ${ }^{3,4)}$ Cognitive disability in the acute phase after stroke is a predictive factor for depressive symptoms and a reduced quality of life in the long term. ${ }^{5}$ ) Cognitive disability can also influence motivation and the ability to participate in rehabilitation programs, thereby reducing the chances of a return to the community. Therefore, cognitive recovery by rehabilitation in the early phase after stroke is important for older patients.

Rehabilitation programs for patients with stroke are usually facilitated by an interdisciplinary team comprising a physician, nurse, physical therapist, occupational therapist, speech therapist, and other professionals in related fields. Speech therapists assess, diagnose, and treat disorders of speech, language, social communication, cognitive communication, and swallowing. ${ }^{\text {) }}$

Speech therapy reportedly has a positive effect on recovery from aphasia and on preventing aspiration pneumonia. ${ }^{7-9)}$ However, the effect of speech therapy on cognitive recovery in patients with acute stroke is unclear. Although some

Received: June 5, 2016, Accepted: September 13, 2016, Published online: September 30, 2016

a Department of Rehabilitation Medicine, Setagaya Memorial Hospital, Tokyo, Japan

${ }^{b}$ Department of Dysphagia Rehabilitation, Nihon University School of Dentistry, Tokyo, Japan

${ }^{\mathrm{c}}$ Department of Rehabilitation Medicine, The Jikei University School of Medicine, Tokyo, Japan

${ }^{\mathrm{d}}$ Department of Rehabilitation Medicine, Teikyo University Mizonokuchi Hospital, Tokyo, Japan

Correspondence: Ryo Momosaki, MD, PhD, MPH, Department of Rehabilitation Medicine, The Jikei University School of Medicine,

3-25-8 Nishi-Shimbashi, Minato-Ku, Tokyo 105-8461, Japan, E-mail: momosakiryo@gmail.com

This publication was supported by JSPS KAKENHI Grant Number JP16HP1002.

Copyright (C) 2016 The Japanese Association of Rehabilitation Medicine 
studies have reported a correlation between rehabilitation intensity and recovery of physical function in patients with acute stroke, ${ }^{10)}$ the effect of rehabilitation intensity on cognitive recovery is unclear. If speech therapy is effective for cognitive recovery in older patients with acute stroke, speech therapy in acute stroke rehabilitation should be given more consideration.

We hypothesized that a greater amount of speech therapy time during acute stroke rehabilitation might be correlated with better cognitive recovery. We performed a retrospective cohort study to clarify the real-world effectiveness of the amount of speech therapy time in acute stroke rehabilitation on cognitive recovery in a clinical practice setting. We used the Japan Rehabilitation Database because it contains realworld clinical practice data from a large number of acute hospitals throughout Japan.

\section{METHODS}

\section{Data Source}

The Japan Rehabilitation Database was developed with financial support from the Ministry of Health, Labour and Welfare of Japan. ${ }^{11)}$ Clinical data have been collected for rehabilitation inpatients discharged from participating hospitals since 2005. The database is divided into different sections such as stroke, hip fracture, and spinal cord injury. The database is recorded voluntarily by hospitals listed in the Japan Association of Rehabilitation Database. The database consists of continuous samples in these hospitals. Because of the anonymous nature of the data, informed consent was waived for the present study. The medical staff (physicians, therapists, and nurses) at each hospital record the data and send them to the office of the Japan Association of Rehabilitation Database. The Association extracts and sends the data to researchers. The database for stroke patients mainly includes the following patient characteristics: age, sex, Functional Independence Measure (FIM) score (ranges from 18 for totally dependent to 126 for totally independent), ${ }^{12)}$ length of stay at the acute hospital, days from stroke onset, type of stroke, amount of daily speech therapy time and other therapy time, modified Rankin Scale (mRS) score (ranges from 1 for no significant disability to 5 for severe disability), ${ }^{13)}$ Glasgow Coma Scale (GCS) score, ${ }^{14)}$ comorbidities, and history of stroke.

\section{Patients}

For this study, the clinical data of patients who were admitted with a diagnosis of stroke from December 2005 to
September 2014 were collected from the Japan Rehabilitation Database. We included patients for whom the following data were recorded: admission within 3 days of onset, start of speech therapy within 7 days of admission, and information on cognitive FIM score at admission and discharge from the acute hospital.

\section{Speech Therapy}

Rehabilitation physicians in Japan prescribe speech therapy for patients with aphasia, dysphagia, dysarthria, dysphonia and for patients with cognitive impairments involving memory, attention, problem solving, and executive functions. Acute rehabilitation is usually provided to patients on weekdays in Japan.

In the current study, patients were divided into two groups according to the amount of speech therapy time: the high-intensity speech therapy (HI-ST) group and the control group. The HI-ST group comprised patients who underwent speech therapy for an average of $\geq 20 \mathrm{~min} /$ day. The control group comprised patients who underwent speech therapy for an average of $<20 \mathrm{~min} /$ day. The average daily speech therapy time was calculated by dividing the total speech therapy time by the duration of hospitalization in acute hospitals, including days in which no speech therapy took place. Studies of data from acute hospitals in Japan and a stroke rehabilitation unit in Canada showed that patients with stroke usually undergo rehabilitation from both physical therapists and occupational therapists for a total of about $30 \mathrm{~min} / \mathrm{day} .{ }^{15,16)}$ Because there are fewer speech therapists than physical therapists or occupational therapists in Japan, it is possible that patients undergo less speech therapy than they do physical therapy or occupational therapy. The cost of rehabilitation is calculated in 20-min intervals in the Japanese medical insurance system. For these reasons, the patients were divided into two groups with a cutoff of $20 \mathrm{~min}$.

\section{Cognitive Disability}

Cognitive disability was evaluated by the cognitive FIM score. The cognitive FIM score comprises two subscale scores: a communication and a social cognition score. The communication score consists of a comprehension and expression score and ranges from 2 to 14 points. The social cognition score consists of a social interaction, problem solving, and memory score and ranges from 3 to 21 points.

\section{Outcome Measures}

The primary clinical outcome in this study was cognitive FIM efficiency. ${ }^{17)}$ The secondary clinical outcomes were 
cognitive FIM subscale efficiency (communication and social cognition efficiency), cognitive FIM gain, duration of hospitalization, and discharge status. Evaluation of the cognitive FIM score was performed and recorded at admission and at discharge from the acute hospital. The outcome measure of this study, the cognitive FIM efficiency, was calculated using the following equation: (discharge cognitive FIM score - admission cognitive FIM score)/days of hospitalization. Likewise, communication and social cognition efficiencies were calculated using the following equations: (discharge communication FIM score - admission communication FIM score)/days of hospitalization, and (discharge social cognition FIM score - admission social cognition FIM score)/days of hospitalization, respectively. Cognitive FIM gain was calculated using the following equation: discharge cognitive FIM score - admission cognitive FIM score. The discharge status was divided into the following categories: home, facility, other hospital, death, and unknown.

\section{Statistical Analyses}

The demographic and clinical characteristics of the patients were compared between the HI-ST group and the control group using the chi-square test for categorical variables and using the unpaired $t$-test for continuous variables. Multivariate linear regression analysis for cognitive FIM efficiency as the dependent variable was performed to calculate the correlation coefficients of the following independent variables: age, sex, type of stroke, days to admission after onset, $\mathrm{mRS}$ score before admission and at admission, motor and cognitive FIM score at admission, HI-ST group (or control group), daily time undergoing other therapy by a physical therapist or occupational therapist, comorbidities (hypertension, diabetes mellitus, and atrial fibrillation), and GCS score at admission. Multivariate linear regression analysis was also performed for both communication efficiency and social cognition efficiency as the dependent variables. Furthermore, subgroup analyses were performed after dividing the patients into two groups by age at admission $(<75$ and $\geq 75$ years of age, defined as early elderly or late elderly, respectively, by the World Health Organization). We used generalized estimation equations to account for clustering of observations within hospitals and to provide more accurate confidence intervals (CIs). We used SPSS 23.0 software (IBM SPSS Inc., Armonk, NY, USA) for all analyses. The threshold for significance was $\mathrm{P}<0.05$.

\section{RESULTS}

During the study period, there were 16,791 patients with stroke, 2768 with hip fracture, and 4124 with spinal cord injury recorded in the database. Of these, 9951 stroke patients in 37 participating acute hospitals were identified for the present study. Excluded from the analysis were 1102 patients who were not admitted within 3 days of onset, 3002 patients who did not undergo speech therapy, 559 patients who did not start speech therapy within 7 days of admission, and 1947 patients with incomplete cognitive FIM score data. A total of 3341 patients in 12 participating acute hospitals remained eligible for analysis (Fig. 1). In the final analysis, $75 \%$ of patients were registered from the top three hospitals.

Table 1 shows the clinical characteristics of the study patients. The HI-ST group comprised 1778 patients (53.2\%). The age and mRS score before admission and at admission were significantly lower for patients in the HI-ST group than in the control group. The motor FIM score at admission, cognitive FIM score at admission, communication FIM score at admission, daily time undergoing other therapy, and GCS score at admission were significantly higher in patients in the HI-ST group than in the control group. There were no significant differences in sex, days to admission after onset, social cognition FIM score at admission, comorbidities (hypertension, diabetes, or atrial fibrillation), right-sided body paralysis, or history of stroke between the two groups. There was a significant difference in the types of stroke between the two groups.

Table 2 shows a comparison of outcomes between the two groups. The HI-ST group had significantly higher scores than the control group in cognitive FIM efficiency (mean \pm standard deviation, $0.17 \pm 0.37$ vs $0.10 \pm 0.31 ; \mathrm{P}<0.001$ ), communication FIM efficiency $(0.06 \pm 0.17$ vs $0.04 \pm 0.13$; $\mathrm{P}=0.001)$, and social cognition FIM efficiency $(0.11 \pm 0.28$ vs $0.07 \pm 0.21 ; \mathrm{P}<0.001)$. In addition, the HI-ST group had significantly higher scores in cognitive FIM gain (4.30 \pm 6.74 vs $2.94 \pm 6.07$; $\mathrm{P}<0.001)$, a shorter duration of hospitalization $(29.93 \pm 19.56$ vs $34.69 \pm 24.08 ; \mathrm{P}<0.001)$, and more patients who were discharged to home than the control group (36.2\% vs $26.5 \%)$.

Table 3 shows the multivariate linear regression analysis results for cognitive outcome. Multivariate linear regression analysis identified the HI-ST group as a significant factor in cognitive FIM efficiency (coefficient, 0.030; 95\% CI, 0.004-0.056; $\mathrm{P}=0.026$ ). Additionally, the HI-ST group was identified as a significant factor in communication FIM efficiency (coefficient, 0.012; 95\% CI, 0.002-0.022; P = 0.019) 


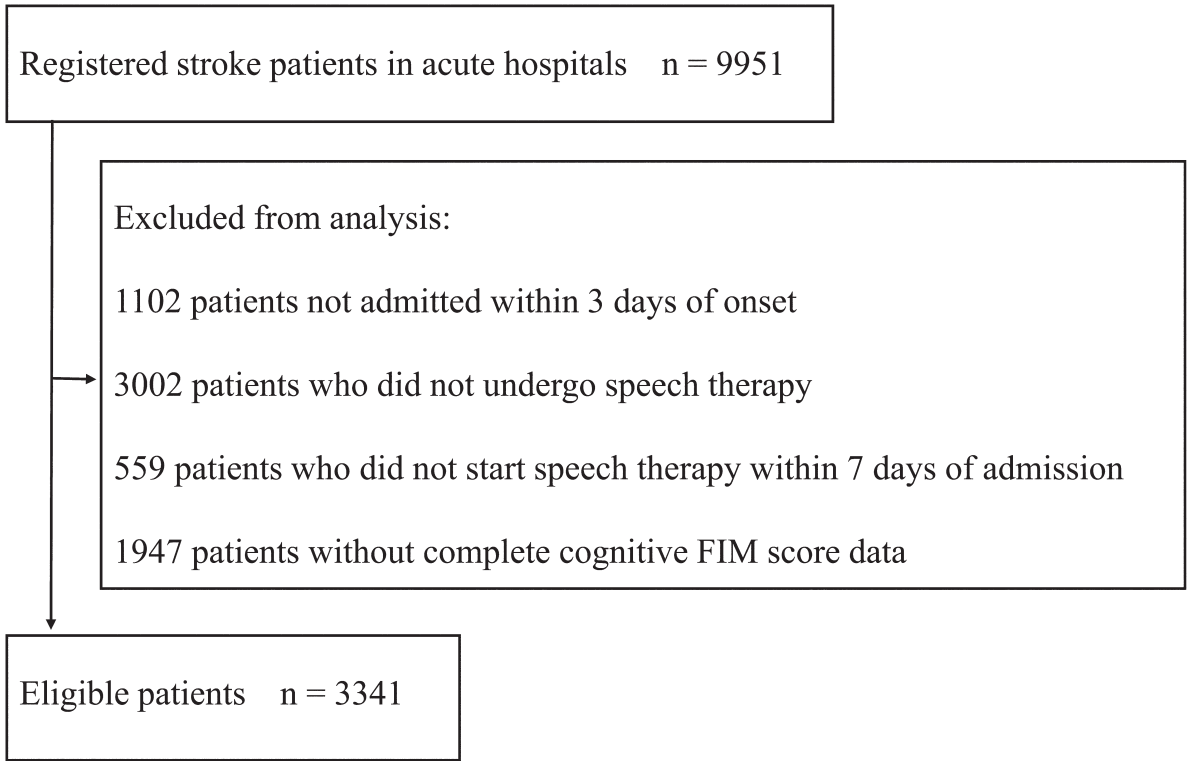

Fig. 1. Patient selection from the Japan Rehabilitation Database.

and social cognition FIM efficiency (coefficient, 0.018; 95\% CI, 0.000-0.035; $\mathrm{P}=0.048$ ). The results of subgroup analysis showed that the HI-ST group was a significant factor for cognitive FIM efficiency $(\mathrm{P}<0.001)$ and social cognition FIM efficiency $(\mathrm{P}<0.001)$ in early-elderly patients (age $<75$ years) (Table 4).

\section{DISCUSSION}

We used a large rehabilitation inpatient database to investigate the real-world effectiveness of the amount of speech therapy time on cognitive FIM efficiency in older patients with acute stroke. The present study showed that providing speech therapy for an average of $\geq 20 \mathrm{~min} /$ day was associated with higher cognitive FIM efficiency than providing speech therapy for an average of $<20 \mathrm{~min} /$ day to older acute stroke patients. Furthermore, longer speech therapy times were associated with higher communication and social cognition FIM efficiencies as subscales of cognitive FIM efficiency.

The database used in the present study, the Japan Rehabilitation Database, included real-world practical data for a large number of patients under a multicenter registry of a number of hospitals across Japan. Therefore, the strong statistical power of this study allows us to draw definite conclusions. In addition, generalized estimating equations were used in this study to account for the potential correlation of outcomes within hospitals.

Previous clinical studies in other rehabilitation fields have identified the important role of intensive rehabilitative treatment, which often leads to better functional recovery. Although one study showed no effect of intensive rehabilitative treatment ( $2 \mathrm{~h} /$ day vs. $45 \mathrm{~min} /$ day) in patients with acute hemispherical ischemic stroke causing severe disabilities, ${ }^{18)}$ several studies have reported that the intensity of acute exercise therapy for patients with physical impairment at a moderate or higher level has a favorable effect on physical function recovery. ${ }^{19,20)}$ Additionally, the total amount of time provided by occupational therapists was found to contribute significantly to gains in the FIM score during hospitalization. ${ }^{16)}$ To the best of our knowledge, our study is the first clinical study to examine the relationship between the amount of speech therapy time and cognitive recovery in older patients with acute stroke.

The main reason for the significant association between the speech therapy time and cognitive recovery remains unclear because the database did not provide sufficient detail for further investigation. However, several reasons for this association can be put forward. Many patients with acute stroke have dysarthria (i.e., a motor speech disorder) caused by face or tongue paralysis. ${ }^{21)}$ Speech therapy for dysarthria often involves exercises of the tongue, lips, and jaw. These approaches might have influenced communication FIM efficiency. Many patients with acute stroke also have disturbance of consciousness. ${ }^{22)}$ Rehabilitation provided by speech therapists for patients with consciousness disturbance often involves passive exercises involving the face and oral cavity. 
Table 1. Patient characteristics

\begin{tabular}{|c|c|c|c|c|}
\hline & $\begin{array}{c}\text { Total } \\
(\mathrm{n}=3341)\end{array}$ & $\begin{array}{l}\text { HI-ST group } \\
(\mathrm{n}=1778)\end{array}$ & $\begin{array}{c}\text { Control group } \\
(\mathrm{n}=1563)\end{array}$ & P-value \\
\hline Age at admission (years) & $76.6 \pm 12.0$ & $75.8 \pm 12.5$ & $77.5 \pm 11.4$ & $<0.001$ \\
\hline Sex, female $(\%)$ & $1591(47.6)$ & $840(47.2)$ & $751(48.0)$ & 0.642 \\
\hline Days to admission from onset & $1.2 \pm 0.5$ & $1.2 \pm 0.5$ & $1.2 \pm 0.5$ & 0.901 \\
\hline Daily speech therapy time (min/day) & $24.8 \pm 33.8$ & $36.4 \pm 42.8$ & $11.6 \pm 5.0$ & $<0.001$ \\
\hline Daily other therapy time (min/day) & $64.8 \pm 39.8$ & $83.4 \pm 36.8$ & $45.0 \pm 32.0$ & $<0.001$ \\
\hline Motor FIM score at admission & $24.6 \pm 17.4$ & $25.4 \pm 17.7$ & $23.8 \pm 17.1$ & 0.010 \\
\hline Cognitive FIM score at admission & $16.0 \pm 9.5$ & $16.3 \pm 9.0$ & $15.8 \pm 1.0$ & 0.014 \\
\hline Communication FIM score at admission & $7.3 \pm 4.1$ & $7.5 \pm 3.9$ & $7.1 \pm 4.4$ & 0.002 \\
\hline Social cognition FIM score at admission & $8.7 \pm 5.8$ & $8.7 \pm 5.6$ & $8.7 \pm 6.0$ & 0.827 \\
\hline mRS score before admission & $1.4 \pm 1.6$ & $1.3 \pm 1.5$ & $1.5 \pm 1.7$ & $<0.001$ \\
\hline mRS score at admission & $4.5 \pm 1.4$ & $4.2 \pm 1.2$ & $4.7 \pm 1.4$ & $<0.001$ \\
\hline GCS score at admission & $12.8 \pm 2.9$ & $13.0 \pm 2.7$ & $12.5 \pm 3.1$ & $<0.001$ \\
\hline Type of stroke & & & & $<0.001$ \\
\hline Cerebral infarction & $2113(63.2)$ & $1136(63.9)$ & $977(62.5)$ & \\
\hline Cerebral hemorrhage & $886(26.5)$ & $491(27.6)$ & $395(25.3)$ & \\
\hline Subarachnoid hemorrhage & $125(3.7)$ & $69(3.9)$ & $56(3.6)$ & \\
\hline Others & $217(6.5)$ & $82(4.6)$ & $135(8.6)$ & \\
\hline Right-sided body paralysis & $1202(36.0)$ & $655(36.9)$ & $547(35.0)$ & 0.268 \\
\hline \multicolumn{5}{|l|}{ Comorbidities } \\
\hline Hypertension & $2191(65.6)$ & $1171(65.9)$ & $1020(65.3)$ & 0.715 \\
\hline Atrial fibrillation & $723(21.6)$ & $400(22.5)$ & $323(20.7)$ & 0.200 \\
\hline Diabetes & $630(18.9)$ & $323(18.2)$ & $307(19.6)$ & 0.277 \\
\hline History of stroke & $115(3.4)$ & $62(3.6)$ & $53(3.6)$ & 0.995 \\
\hline
\end{tabular}

FIM, Functional Independence Measure; GCS, Glasgow Coma Scale; HI-ST, high-intensity speech therapy; mRS, modified Rankin Scale. Values are expressed as mean \pm SD or number of patients $(\%)$.

Table 2. Comparison of outcomes

\begin{tabular}{lcccc}
\hline & Total $(\mathrm{n}=3341)$ & $\begin{array}{c}\text { HI-ST group } \\
(\mathrm{n}=1778)\end{array}$ & $\begin{array}{c}\text { Control group } \\
(\mathrm{n}=1563)\end{array}$ & P-value \\
\hline Cognitive FIM efficiency & $0.14 \pm 0.34$ & $0.17 \pm 0.37$ & $0.10 \pm 0.31$ & $<0.001$ \\
Communication FIM efficiency & $0.05 \pm 0.16$ & $0.06 \pm 0.17$ & $0.04 \pm 0.13$ & 0.001 \\
Social cognition FIM efficiency & $0.09 \pm 0.25$ & $0.11 \pm 0.28$ & $0.07 \pm 0.21$ & $<0.001$ \\
Cognitive FIM gain & $3.66 \pm 6.47$ & $4.30 \pm 6.74$ & $2.94 \pm 6.07$ & $<0.001$ \\
Duration of hospitalization (days) & $32.16 \pm 21.96$ & $29.93 \pm 19.56$ & $34.69 \pm 24.08$ & $<0.001$ \\
Discharge Status & & & & $<0.001$ \\
Home & $1058(31.7)$ & $644(36.2)$ & $414(26.5)$ & $112(7.2)$ \\
Facility & $215(6.4)$ & $103(5.8)$ & $1003(64.2)$ & $13(0.8)$ \\
Other hospital & $2022(60.5)$ & $1019(57.3)$ & $21(1.3)$ & \\
Death & $20(0.6)$ & $7(0.4)$ & $5(0.3)$ & \\
Unknown & $26(0.8)$ & & \\
\hline
\end{tabular}

Values are expressed as mean \pm SD or number of patients $(\%)$. 
Table 3. Multivariate linear regression analysis for cognitive outcome

\begin{tabular}{lccccc}
\hline & $\mathrm{B}$ & $95 \% \mathrm{CI}(\mathrm{B})$ & Coefficient (beta) & $95 \%$ CI (beta) & P-value \\
\hline Cognitive FIM efficiency & 0.030 & $0.004-0.056$ & 1.030 & $1.004-1.057$ & 0.026 \\
Communication FIM efficiency & 0.012 & $0.002-0.022$ & 1.012 & $1.002-1.022$ & 0.019 \\
Social cognition FIM efficiency & 0.018 & $0.000-0.035$ & 1.018 & $1.000-1.036$ & 0.048 \\
\hline
\end{tabular}

$\mathrm{B}$, partial regression coefficient; CI, confidence interval.

Table 4. Subgroup analysis of multivariate linear regression analysis for cognitive outcome

\begin{tabular}{lccccc}
\hline & $\mathrm{B}$ & $95 \%$ CI (B) & Coefficient (beta) & $95 \%$ CI (beta) & P-value \\
\hline $\begin{array}{l}\text { Age at admission } \geq 75 \text { years } \\
(\mathrm{n}=2135)\end{array}$ & & & & & \\
$\quad$ Cognitive FIM efficiency & 0.013 & $-0.009-0.035$ & 1.013 & $0.991-1.036$ & 0.250 \\
$\quad \begin{array}{l}\text { Communication FIM efficiency } \\
\quad \text { Social cognition FIM efficiency }\end{array}$ & 0.009 & $-0.001-0.020$ & 1.009 & $0.999-1.020$ & 0.080 \\
$\begin{array}{l}\text { Age at admission }<75 \text { years } \\
(\mathrm{n}=1206)\end{array}$ & & $-0.014-0.021$ & 1.004 & $0.986-1.002$ & 0.670 \\
$\quad$ Cognitive FIM efficiency & 0.059 & $0.028-0.091$ & 1.061 & $1.029-1.095$ & $<0.001$ \\
$\quad$ Communication FIM efficiency & 0.017 & $-0.001-0.036$ & 1.017 & $0.999-1.037$ & 0.070 \\
$\quad$ Social cognition FIM efficiency & 0.042 & $0.029-0.055$ & 1.043 & $1.029-1.057$ & $<0.001$ \\
\hline
\end{tabular}

The face and oral cavity area in the brain cortex is larger than that of the upper limbs and legs. ${ }^{23)}$ Additionally, lip and tongue exercises ${ }^{24,25)}$ and taste stimuli ${ }^{26)}$ result in major brain activation. Thus, it is possible that increased exercise and greater stimuli to the face and oral cavity during speech therapy in patients with stroke had positive effects on recovery of consciousness and on ameliorating cognitive disability as a result of the associated large amounts of brain activation. Moreover, some stroke patients might undergo specialized rehabilitation to recover cognitive ability (e.g., attention and memory) using a compensatory approach. ${ }^{27,28)}$ The effectiveness of speech therapy on aphasia has been reported previously. ${ }^{78)}$ In addition, aphasia therapy was effective for the recovery of memory and for improving attention, problem solving, and executive functions that may sometimes require language-related thinking. ${ }^{29)}$ However, the number of patients with aphasia was unclear in the present study. Because the number of patients with right-sided paralysis who possibly had aphasia was not significantly different between the HI-ST and control groups, the effectiveness of HI-ST might be caused not only by aphasia therapy but also by a comprehensive speech therapy program.

The results of the subgroup analysis showed that the speech therapy time was not associated with cognitive FIM efficiency for patients aged $\geq 75$ years. The reason for this finding may be that cognitive functions such as fluid intelligence, attention, memory, and executive functioning decrease with age. ${ }^{30)}$ Patients aged $>75$ years may have had low trainability with respect to rehabilitation by speech therapists. In addition, the statistical power was likely reduced when the sample size was decreased by division into two subgroups.

Because of the small number of speech therapists in Japan, many patients with acute stroke may not be provided enough speech therapy in real-world practice. Thus, based on our finding of the important role of speech therapy for cognitive recovery, we recommend providing a greater amount of speech therapy to older patients with acute stroke. If adequate speech therapy is provided during acute medical care, the quality of stroke rehabilitation will likely be improved.

Several limitations of this study should be acknowledged. First, because the database used in this study did not have data for all acute stroke patients who received speech therapy in Japan, and because the database was constructed without random sampling, the generalizability of these findings might be limited. Second, speech therapy time might be shorter if patients have a serious cognitive impairment, and this represents a selection bias. This antagonistic bias would cause underestimation of the effectiveness of HI-ST rather than overestimation. This problem was not considered to be serious in the current study. Third, the database lacks detailed information about the diagnosis of impairment and about the rehabilitation programs used in speech therapy. Therefore, the types of speech therapy programs that are effective for recovery of cognitive ability remain unclear. Consequently, 
we focused on the amount of speech therapy in the current study. We could clarify the amount of speech therapy time that may be needed for acute stroke rehabilitation. Hopefully, our findings will contribute to the creation of future policies for acute stroke rehabilitation. Fourth, there was deviation in the distribution of patients among the hospitals. The amount of speech therapy time might reflect the policy of those hospitals that contributed large numbers of eligible patients to the database. Therefore, we adjusted such correlations (clustering) of data within a hospital using generalized estimating equations. Finally, the database lacks information about medication, cognitive ability before admission, and the brain region affected by stroke; these factors may influence the recovery of cognitive ability.

\section{CONCLUSION}

In conclusion, our analysis of real-world data in the clinical practice setting has shown that speech therapy for an average of $\geq 20 \mathrm{~min} /$ day was associated with good cognitive recovery in older acute stroke patients who underwent speech therapy.

\section{ACKNOWLEDGEMENTS}

This study was supported by a grant from the Japan Society for Promotion of Science KAKENHI (Grant No. 15K01395). We would like to thank the Japan Association of Rehabilitation Database for the provision of database services. The Japan Association of Rehabilitation Database did not provide any opinions regarding this study.

\section{CONFLICTS OF INTEREST}

The authors declare that there are no conflicts of interest.

\section{REFERENCES}

1. Strong K, Mathers C, Bonita R: Preventing stroke: saving lives around the world. Lancet Neurol 2007;6:182187. [Medline] [CrossRef]

2. Reitz C, Bos MJ, Hofman A, Koudstaal PJ, Breteler MM: Prestroke cognitive performance, incident stroke, and risk of dementia: the Rotterdam Study. Stroke 2008;39:36-41. [Medline] [CrossRef]

3. Jokinen H, Melkas S, Ylikoski R, Pohjasvaara T, Kaste M, Erkinjuntti T, Hietanen M: Post-stroke cognitive impairment is common even after successful clinical recovery. Eur J Neurol 2015;22:1288-1294. [Medline] [CrossRef]
4. Bugarski Ignjatovic V, Semnic M, Gebauer Bukurov K, Kozic D: Cognitive impairment and functional ability in the acute phase of ischemic stroke. Eur Rev Med Pharmacol Sci 2015;19:3251-3256. [Medline]

5. Nys GM, van Zandvoort MJ, van der Worp HB, de Haan EH, de Kort PL, Jansen BP, Kappelle LJ: Early cognitive impairment predicts long-term depressive symptoms and quality of life after stroke. J Neurol Sci 2006;247:149-156. [Medline] [CrossRef]

6. Ashley J, Duggan M, Sutcliffe N: Speech, language, and swallowing disorders in the older adult. Clin Geriatr Med 2006;22:291-310, viii. [Medline] [CrossRef]

7. Godecke E, Rai T, Ciccone N, Armstrong E, Granger A, Hankey GJ: Amount of therapy matters in very early aphasia rehabilitation after stroke: a clinical prognostic model. Semin Speech Lang 2013;34:129-141. [Medline] [CrossRef]

8. Brady MC, Kelly H, Godwin J, Enderby P: Speech and language therapy for aphasia following stroke. Cochrane Database Syst Rev 2012;5:CD000425. [Medline]

9. Bax L, McFarlane M, Green E, Miles A: Speech-language pathologist-led fiberoptic endoscopic evaluation of swallowing: functional outcomes for patients after stroke. J Stroke Cerebrovasc Dis 2014;23:e195-e200. [Medline] [CrossRef]

10. $\mathrm{Hu} \mathrm{MH}$, Hsu SS, Yip PK, Jeng JS, Wang YH: Early and intensive rehabilitation predicts good functional outcomes in patients admitted to the stroke intensive care unit. Disabil Rehabil 2010;32:1251-1259. [Medline] [CrossRef]

11. Inoue $\mathrm{Y}$, Jeong $\mathrm{S}$, Kondo $\mathrm{K}$ : Changes in hospital performance after implementation of pay-for-performance in Japan. Clin Audit 2011;3:17-23.

12. Chumney D, Nollinger K, Shesko K, Skop K, Spencer M, Newton RA: Ability of Functional Independence Measure to accurately predict functional outcome of stroke-specific population: systematic review. J Rehabil Res Dev 2010;47:17-29. [Medline] [CrossRef]

13. Sulter G, Steen C, De Keyser J: Use of the Barthel index and modified Rankin scale in acute stroke trials. Stroke 1999;30:1538-1541. [Medline] [CrossRef]

14. Teasdale G, Jennett B: Assessment of coma and impaired consciousness. A practical scale. Lancet 1974;2:81-84. [Medline] [CrossRef]

15. Matsui $H$, Hashimoto $H$, Horiguchi $H$, Yasunaga $H$, Matsuda S: An exploration of the association between very early rehabilitation and outcome for the patients 
with acute ischaemic stroke in Japan: a nationwide retrospective cohort survey. BMC Health Serv Res 2010;10:213. [Medline] [CrossRef]

16. Foley N, McClure JA, Meyer M, Salter K, Bureau Y, Teasell R: Inpatient rehabilitation following stroke: amount of therapy received and associations with functional recovery. Disabil Rehabil 2012;34:2132-2138. [Medline] [CrossRef]

17. Koh GC, Chen CH, Petrella R, Thind A: Rehabilitation impact indices and their independent predictors: a systematic review. BMJ Open 2013;3:e003483. [Medline] [CrossRef]

18. Di Lauro A, Pellegrino L, Savastano G, Ferraro C, Fusco M, Balzarano F, Franco MM, Biancardi LG, Grasso A: A randomized trial on the efficacy of intensive rehabilitation in the acute phase of ischemic stroke. $\mathrm{J}$ Neurol 2003;250:1206-1208. [Medline] [CrossRef]

19. Kwakkel G, van Peppen R, Wagenaar RC, Wood Dauphinee S, Richards C, Ashburn A, Miller K, Lincoln N, Partridge C, Wellwood I, Langhorne P: Effects of augmented exercise therapy time after stroke: a metaanalysis. Stroke 2004;35:2529-2539. [Medline] [CrossRef]

20. Sivenius J, Pyörälä K, Heinonen OP, Salonen JT, Riekkinen P: The significance of intensity of rehabilitation of stroke-a controlled trial. Stroke 1985;16:928-931. [Medline] [CrossRef]

21. Perry L, Love CP: Screening for dysphagia and aspiration in acute stroke: a systematic review. Dysphagia 2001;16:7-18. [Medline] [CrossRef]

22. Alonso A, Ebert AD, Kern R, Rapp S, Hennerici MG, Fatar M: Outcome predictors of acute stroke patients in need of intensive care treatment. Cerebrovasc Dis 2015;40:10-17. [Medline] [CrossRef]

23. Penfield W, Boldrey E: Somatic motor and sensory representation in the cerebral cortex of man as studied by electrical stimulation. Brain 1937;60:389-443. [CrossRef]

24. Ogura E, Matsuyama M, Goto TK, Nakamura Y, Koyano K: Brain activation during oral exercises used for dysphagia rehabilitation in healthy human subjects: a functional magnetic resonance imaging study. Dysphagia 2012;27:353-360. [Medline] [CrossRef]

25. Corfield DR, Murphy K, Josephs O, Fink GR, Frackowiak RS, Guz A, Adams L, Turner R: Cortical and subcortical control of tongue movement in humans: a functional neuroimaging study using fMRI. J Appl Physiol 1985 1999;86:1468-1477. [Medline]

26. Okamoto M, Dan H, Clowney L, Yamaguchi Y, Dan I: Activation in ventro-lateral prefrontal cortex during the act of tasting: an fNIRS study. Neurosci Lett 2009;451:129-133. [Medline] [CrossRef]

27. Sohlberg MM, Mateer CA: Effectiveness of an attention-training program. J Clin Exp Neuropsychol 1987;9:117-130. [Medline] [CrossRef]

28. Nair RD, Lincoln NB: Cognitive rehabilitation for memory deficits following stroke. Cochrane Database Syst Rev 2007;CD002293. [Medline]

29. Baldo JV, Paulraj SR, Curran BC, Dronkers NF: Impaired reasoning and problem-solving in individuals with language impairment due to aphasia or language delay. Front Psychol 2015;6:1523. [Medline] [CrossRef]

30. Harada CN, Natelson Love MC, Triebel KL: Normal cognitive aging. Clin Geriatr Med 2013;29:737-752. [Medline] [CrossRef] 